Пронин Э.А.

\title{
ЭКОНОМИЧЕСКАЯ БЕЗОПАСНОСТЬ ГОСУДАРСТВА: ИСТОКИ И КОНЦЕПТУАЛЬНЫЕ СВЯЗИ
}

Аннотация: Предметом статьи являются проблемы правового и организационного характера, связанные с правовым и организационным регулированием современной экономки. Автором подробно проводится meоретико-правовой анализ концепций правового регулирования экономических отношений с позиции обеспечения ее безопасности. В статье рассматриваются авторские позиции относительно понятия регулирование экономической безопасности. Основное внимание в статье уделяется разработки методов и методологии государственного воздействия на экономические отношения с целью обеспечение экономической безопасности. Кроме того, в статье проводится теоретико-правовой анализ понятий концепций развития экономической безопасности в современных условиях. Рассматриваются авторские позиции относительно толкования и правовой регламентации данных категорий. Методологическую основу статьи составили современные достижения теории познания. В процессе исследования применялись общефилософский, теоретический, общефилософские методы (диалектика, системный метод, анализ, синтез, аналогия, дедукция, наблюдение, моделирование), традиционно правовые методы (формально-логический), а также методы, используемые в конкретно-социологических исследованиях (статистические, экспертные оценки и др.). Основной вывод, который сделан по итогам исследования, состоит в том, что в настоящее время для обеспечения правопорядка в сфрере экономки необходимо совершенствовать формы и методы обеспечения экономической безопасности. Основным вкладом, который сделан авторами в настоящей статье это необходимость развития государственного регулирования экономической безопасности. Новизна статьи заключается в разработке предложений по развитию форм и методов государственного регулирования экономики, а также создание правовых и организационных гарантий законности в сорере обеспечения экономической безопасности.

Ключевые слова: Экономика, безопасность, концепция, регулирование, исток, государство, метод, политика, защита, государственный.

Review: The article focuses on the problems of legal and organizational measures related to legal and organizational regulation of the modern economy. The author conducts a theoretical and legal analysis of the concepts of legal regulation of economic relations from the viewpoint of security provision. The article describes the author's attitudes towards the concept of economic security management. The main attention is paid to the development of meth- 
ods and methodology of state influence on economic relations for the purpose of economic security provision. In addition, the article presents a theoretical and legal analysis of economic security development concepts in modern conditions. The paper describes the author's position concerning the interpretation and legal regulation of these categories. The methodology of the research is based on the recent achievements of epistemology. The author uses the general philosophical and theoretical methods (dialectics, the systems method, analysis, synthesis, analogy, deduction, observation, modeling), the traditional legal methods (formal logic), and the methods used in special sociological research (the statistical mehtod, expert evaluation, etc.). The author concludes that at present in order to provide law and order in the economic sphere, forms and methods of economic security provision should be enhanced. The main contribution of the author is the declared need for the development of state regulation of economic security. The novelty of the article lies in the proposals for the development of forms and methods of state regulation of economy and the creation of legal and institutional guarantees of legality in the sphere of economic security.

Keywords: Protection, policy, method, state, source, regulation, concept, security, economy, government.

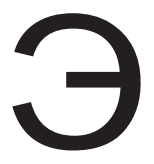

кономическая безопасность - это такое состояние национальной экономики, при котором обеспечиваются защита национальных интересов, устойчивость к внутренним и внешним угрозам, способность к развитию и защищенность жизненно важных интересов людей, общества, государства. Под жизненно важными интересами в данном контексте понимают совокупность потребностей, которые обеспечивают существование и прогрессивное развитие личности, общества, государства. Экономическая безопасность является одной из составляющих национальной безопасности, которая охватывает также оборонную, экологическую безопасность. Основными задачами экономической безопасности являются: обеспечение пропорционального и непрерывного экономи- ческого роста, обуздание инфляции и безработицы, фрормирование эффективной структуры экономики и развитого рынка ценных бумаг, сокращение дефицита бюджета и государственного долга, обеспечение социальной защиты и повышения качества жизни населения, поддержание устойчивости национальной валюты. Эти задачи определяют стратегию экономической безопасности как формирование и обоснование стратегических приоритетов, национальных интересов, средств и механизмов решения проблем. Объектами экономической безопасности является государство, общество, граждане, предприятия, учреждения и организации, территории, отдельные составляющие экономической безопасности. Основным субъектом экономической безопасности выступает государство, которое 
осуществляет свои функции в этой области через органы законодательной, исполнительной и судебной ветвей власти. В системе экономической безопасности определяющую роль играют национальные экономические интересы, их приоритеты. Для определения национальных экономических интересов необходимо: анализ текущего состояния экономики и выявление тенденций развития; моделирования и прогнозирования социально-экономического развития; корректировке мер государственного регулирования с целью достижения желаемых целей. В указанных действиях особо важной является разработка системы экономических показателей, которые бы предоставляли количественную оценку социальноэкономического развития страны. их обязательно надо отражать в действующей статистике.

Существует тесная взаимосвязь экономической безопасности с системой национально-государственных интересов. Именно через категорию национально-государственных интересов сплетаются воедино проблемы экономического потенциала и экономической мощи государства: состояние генофонда нации, предпосылки и условия ее физического здоровья и социально-культурного процветания; геополитические и геоэкономические позиции страны в современном мире [1]. Несомненно, главным элементом, обеспечивающим экономическую безопасность любой страны, являются человеческие ресурсные только в количественном (катастрофически снижающемся), но и в качественном их выражении. К сожалению, здоровье народонаселения России существенно хуже, чем в индустриально развитых странах. В целом по интегральному показателю здоровья россияне находятся на 68-м месте в мире. Средняя трудоспособность русского рабочего, если оценивать по количеству лет работы, потерям рабочего времени в следствии заболеваний и несчастных случаев, энергичности на работе, в два раза ниже, чем рабочего США.

Экономическую безопасность, непосредственно связанную с задачами обеспечения обороноспособности страны, обычно рассматривают как военно-экономическую безопасность. Военно-экономическая безопасность подразумевает такое положение военного сектора экономики, которое гарантирует достаточный уровень военного потребления в период войн и вооруженных конфликтов и гарантирует в мирное время удовлетворение оборонных потребностей в пределах разумной достаточности. Понятно, что решение данной сложной задачи зависит от уровня и высококачественного состояния государственной экономики в целом.

Содержание понятия «экономическая безопасность РФ» может быть рассмотрено в сравнительно статичном состоянии как комплекс таких важных для государственной экономики элементов, как человеческие ресурсы, технико-производственный, технологический, продовольственный, энергетический, 
административный и информационный элементы [2].

Наиболее вероятными угрозами экономической безопасности Российской Федерации, на локализацию которых должна быть направлена деятельность федеральных органов государственной власти, являются:

1. Увеличение имущественной дифференциации населения и повышение уровня бедности, что ведет к нарушению социального мира и общественного согласия. Достигнутый относительный баланс социальных интересов может быть нарушен в результате действия следующих факторов: расслоение общества на узкий круг богатых и преобладающуюмассу бедных, неуверенных в своем будущем людей; увеличение доли бедных слоев населения в городе по сравнению с деревней, что создает социальную и криминальную напряженность и почву для широкого распространения относительно новых для России негативных явлений - наркомании, организованной преступности, проституции и тому подобного; рост безработицы, что может привести к социальным конфликтам; задержка выплаты заработной платы, остановка предприятий и так далее.

2. Деформированность структуры российской экономики, обусловленная такими фракторами, как: усиление топливно-сырьевой направленности экономики; отставание разведки запасов полез- ных ископаемых от их добычи; низкая конкурентоспособность продукции большинства отечественных предприятий; свертывание производства в жизненно важных отраслях обрабатывающей промышленности, прежде всего в машиностроении; снижение результативности, разрушение технологического единства научных исследований и разработок, распад сложившихся научных коллективов и на этой основе подрыв научно-технического потенциала России; завоевание иностранными фрирмами внутреннего рынка России по многим видам товаров народного потребления; приобретение иностранными фрирмами российских предприятий в целях вытеснения отечественной продукции как с внешнего, так и с внутреннего рынка; рост внешнего долга России и связанное с этим увеличение расходов бюджета на его погашение [3].

3. Возрастание неравномерности социально-экономического развития регионов. Важнейшими факторами этой угрозы являются: объективно существующие различия в уровне социальноэкономического развития регионов, наличие депрессивных, кризисных и отсталых в экономическом отношении районов на фоне структурных сдвигов в промышленном производстве, сопровождающихся резким уменьшением доли обрабатывающих отраслей; нарушение производственном 
- технологических связей между предприятиями отдельных регионов России; увеличение разрыва в уровне производства национального дохода на душу населения между отдельными субъектами Российской Федерации.

4. Криминализация общества и хозяйственной деятельности, вызванная в основном такими факторами, как: рост безработицы, поскольку значительная часть преступлений совершается лицами, не имеющими постоянного источника дохода; сращивание части чиновников государственных органов с организованной преступностью, возможность доступа криминальных структур к управлению определенной частью производства и их проникновения в различные властные структуры; ослабление системы государственного контроля, что привело к расширению деятельности криминальных структур на внутреннем финансовом рынке, в сфере приватизации, экспортно-импортных операций и торговли. Основными причинами, вызывающими возникновение указанных угроз, являются неустойчивость финансового положения предприятий, неблагоприятный инвестиционный климат, охранение инфляционных процессов и другие проблемы, связанные с финансовой дестабилизацией в экономике.

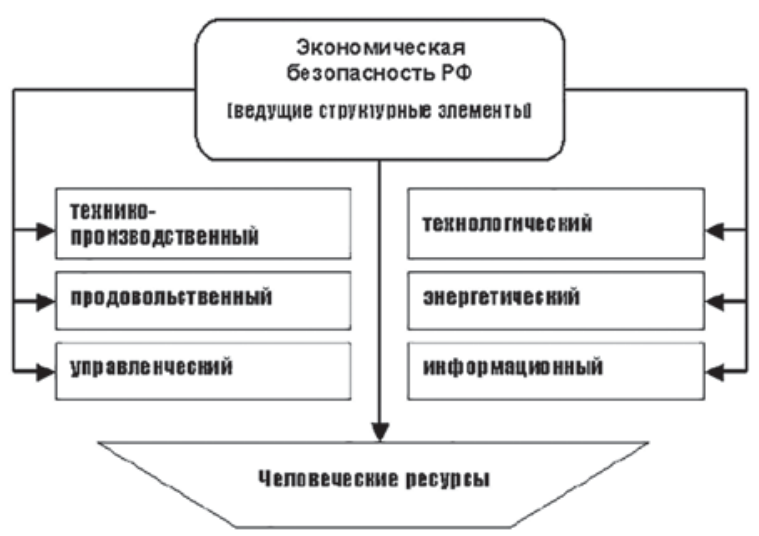

Перед национальной экономической безопасностью ставятся следующие задачи:

- прогнозирование появления внутренних и внешних угроз;

- разработка и реализация необходимых мероприятий по снижению степени влияния внутренних и внешних угроз;

- защита суверенитета и территориальной целостности Российской Федерации;

- разработка и реализация экономической политики, направленной на активизацию экономического роста;

- создание условий научной и технологической независимости;

- обеспечение безопасности человека и гражданина, его прав и свобод;

- повышение эфффективности государственного аппарата;

- поддержание баланса межнациональных отношений;

- создание условий соблюдения законодательства;

- формирование взаимовыгодных отношений с другими государствами; 
- сдерживание военного потенциала страны;

- улучшение экологической обстановки;

- интеграция национальной экономики в мировое хозяйство;

- формирование единого экономического пространства со странами СНГ;

- защита на мировых рынках интересов отечественных производителей;

- формирование режима фринансовокредитной независимости России;

- усиление государственного регулирования иностранных компаний, ведущих хозяйственную деятельность на территории страны;

- фрормирование эфффективного правового поля деятельности хозяйствующих субъектов [4].

Таким образом национальная экономическая безопасность основана на таких основных принципах, как:

независимость национальной экономики. По причине все большего вовлечения национальных экономик в мировую этот принцип может быть выполнен только относительно необходимо достижение состояния относительной независимости национальной экономики. 3адача государства заключается в том, чтобы сорормировать такой уровень развития национальной экономики, который позволяет ей занять конкурентные и равные позиции в мировом хозяйстве; стабильность национальной экономики. Государство должно создать устойчивый рост национальной экономики, исключа- ющий социальные потрясения, усиление роли криминальных структур и создающий режим безопасности для каждого гражданина; устойчивые темпы роста национальной экономики. В современных условиях только постоянный и устойчивый рост может обеспечить приемлемый уровень экономической безопасности, включающий совершенствование производства, профессионализма каждого человека.

Отдельно хотелось бы сказать о подходах к экономической безопасности предприятия, которые можно назвать узкофункциональными. Речь идет о рассмотрении экономической безопасности предприятия с позиции отдельного аспекта его деятельности. Так, высказывается мнение, что важнейшим направлением формирования системы экономической безопасности, в том числе и предприятий, является создание действенного механизма финансовой безопасности [5]. Обосновывается, что учет является одной из основных функций управления, направленной на обеспечение экономической безопасности предприятия, и именно учет исключает возможность прямых хищений без установленных законом последствий, создает информационные условия для осуществления контроля целесообразности и законности использования ресурсов в превентивном, текущем и следующем режимах и оказывает содействие предотвращению реализации угроз, которые снижают экономическую устойчивость предприятий. 
Анализ рассмотренных подходов к проблеме экономической безопасности предприятия позволяет сделать следующие выводы. Экономическая безопасность предприятия складывается из нескольких функциональных составляющих, которые для каждого конкретного предприятия могут иметь различные приоритеты в зависимости от характера существующих угроз. Основным фактором, определяющим состояние экономической безопасности является обладание предприятием устойчивыми конку- рентными преимуществами. Эти преимущества должны соответствовать стратегическим целям предприятия. На основании сделанных выводов можно сорормулировать собственное определение: Экономическая безопасность предприятия - это наличие конкурентных преимуществ, обусловленных соответствием материального, фринансового, кадрового, технико-технологического потенциалов и организационной структуры предприятия его стратегическим целям и задачам.

\section{Библиография:}

1. Арсентьев 3.М. Экономическая безопасность // Обозреватель. - 1998. - №3.

2. Ананишнев В.В. Повышение заработной платы как результат сокращения нерациональных социальных расходов организации: Дис... канд соц наук. - М., 2012.

3. Ананишнев В. В. Социальный пакет работающего населения в России. - М., 2012. 3. 3агашвили В.С. Экономическая безопасность России. - М., 1997 г.

4. Основы экономической безопасности (государство, регион, предприятие, личность) / Под ред. Е.А. Олейникова. - М., 1997

5. Ипполитов К.Х. Экономическая безопасность: стратегия возрождения России. - М., 1996.

6. Кононов Д.А., Кульба В.В., Ковалевский С.С., Косяченко С.А. Формирование сценарных пространств и анализ динамики поведения социально - экономических систем. - М., 1999.

7. Лаптев В.В. Введение в предпринимательское право. - М., 1994

8. Тамбовцев В.Л. Экономическая безопасность хозяйственных систем: структура, проблемы // Вестник МГУ. Серия 6 «Экономика». - 1995. - № 3.

9. Клейн Н.И. Предпринимательское право. - М., 1993.

10. Пронин Э.А., Положенцева И.В., Ананишнев В.В. Современное политическое онлайн-образование в средних общеобразовательных школах. - М., 2003.

11. Ожогин В.Б. Государственное регулирование институциональной инвестиционной среды // Национальная безопасность / nota bene. - 2013. - 5. - C. 156 - 172. DOI: 10.7256/20738560.2013.5.9615.

12. Ашмарина Е.М. Экономическое право: проблемы и перспективы. Доклад на пленарном заседании I Всероссийской межвузовской научно-практической конференции «Экономическое право: теоретические и прикладные аспекты» (Российская академия правосудия, 24-25 января 2014 г.) // Финансовое право и управление. - 2014. - 2. - C. 54 - 76. DOI: 10.7256/2310-0508.2014.2.13294.

\section{References (transliterated):}

1. Arsent'ev Z.M. Ekonomicheskaya bezopasnost' // Obozrevatel'. - 1998. - №3.

2. Ananishnev V.V. Povyshenie zarabotnoi platy kak rezul'tat sokrashcheniya neratsional'nykh sotsial'nykh raskhodov organizatsii: Dis... kand sots nauk. - M., 2012. 
3. Ananishnev V. V. Sotsial'nyi paket rabotayushchego naseleniya v Rossii. - M., 2012. 3. Zagashvili V.S. Ekonomicheskaya bezopasnost' Rossii. - M., $1997 \mathrm{~g}$.

4. Osnovy ekonomicheskoi bezopasnosti (gosudarstvo, region, predpriyatie, lichnost') / Pod red. E.A. Oleinikova. - M., 1997

5. Ippolitov K.Kh. Ekonomicheskaya bezopasnost': strategiya vozrozhdeniya Rossii. - M., 1996.

6. Kononov D.A., Kul'ba V.V., Kovalevskii S.S., Kosyachenko S.A. Formirovanie stsenarnykh prostranstv i analiz dinamiki povedeniya sotsial'no - ekonomicheskikh sistem. - M., 1999.

7. Laptev V.V. Vvedenie v predprinimatel'skoe pravo. - M., 1994

8. Tambovtsev V.L. Ekonomicheskaya bezopasnost' khozyaistvennykh sistem: struktura, problemy // Vestnik MGU. Seriya 6 «Ekonomika». - 1995. - № 3.

9. Klein N.I. Predprinimatel'skoe pravo. - M., 1993.

10. Pronin E.A., Polozhentseva I.V., Ananishnev V.V. Sovremennoe politicheskoe onlain-obrazovanie v srednikh obshcheobrazovatel'nykh shkolakh. - M., 2003.

11. Ozhogin V.B. Gosudarstvennoe regulirovanie institutsional'noi investitsionnoi sredy // Natsional'naya bezopasnost' / nota bene. - 2013. - 5. - C. 156 - 172. DOI: 10.7256/20738560.2013.5.9615.

12. Ashmarina E.M. Ekonomicheskoe pravo: problemy i perspektivy. Doklad na plenarnom zasedanii I Vserossiiskoi mezhvuzovskoi nauchno-prakticheskoi konferentsii «Ekonomicheskoe pravo: teoreticheskie i prikladnye aspekty»(Rossiiskaya akademiya pravosudiya, 24-25 yanvarya 2014 g.) // Finansovoe pravo i upravlenie. - 2014. - 2. - C. 54 - 76. DOI: 10.7256/23100508.2014.2.13294. 